\title{
Patients with essential thrombocytosis during pregnancy: Challenges and therapeutic dilemmas
}

\author{
Theoni Kanellopoulou* \\ Department of Clinical Hematology-Blood Bank-Hemostasis, Onassis Cardiac Surgery Center, Greece
}

\begin{abstract}
Treatment of patients with essential thrombocytosis during pregnancy is challenging and young women are reported to be at increased risk of first trimester abortions and other pregnancy complications. In literature, there are case reports and small case series where the treatment approach differs and the results are conflicting. The addition of low dose aspirin seems to be beneficial in most cases improving pregnancy outcome whereas interferon-a is the cytoreductive drug of choice when platelet control is needed during pregnancy. Anticoagulation with low-molecular weight heparin is not generally recommended and should be considered during the last few weeks of pregnancy and postpartum.
\end{abstract}

\section{Introduction}

Patients with Essential Thrombocytosis (ET) are predominantly women, and up to $20 \%$ are diagnosed before 40 years old at childbearing age. As a result, clinical management during pregnancy is a common issue. It is considered that pregnant woman with $\mathrm{ET}$ are at higher risk of spontaneous abortions and pregnancy complications and there is limited information regarding the outcome of pregnancy which is based on case reports or small case series. Published review studies report live birth rates of $50 \%$ to $70 \%$ and spontaneous abortion rates of $25 \%$ to $50 \%$ [1,2].

The safety of low-dose Aspirin (ASA) in this population is well established. However, the benefit concerning reduction of miscarriages or other pregnancy complications is contradictory. Current recommendations suggest that ASA and cytoreductive therapy should be offered for high-risk pregnancies, especially when there is thrombotic history. Even-though Interferon-a (IFNa) is a Food and Drug Administration (FDA) class $\mathrm{C}$ drug with potential risk to fetus, IFNa is the cytoreductive agent of choice during pregnancy as others like hydroxyurea have a potential teratogenic effect.

This review article presents different treatment approaches on managing patients with ET during pregnancy and the data are collected from published case reports or case series.

\section{Review of the literature}

\section{No treatment}

There have been reported many pregnancies that resulted in healthy newborns without receiving any treatment during pregnancy $[3,4]$. Most of the cases refer to young women where the diagnosis of ET was diagnosed after delivery. The possible reason that ET is underdiagnosed during pregnancy or in patients with known history seems to be "in remission" is the fact that there is a gradually spontaneous decline in platelet count especially in second trimester that possibly facilitate better control in platelet count. Remarkably, the decline of platelet count could be even to normal levels since the reduction is greater that the one seen in normal pregnancies ("normal thrombocytopenia of pregnancy").
However, an increased percentage of abortions were reported [58] and also of pregnancy complications including intrauterine growth retardation (IUGR) [9], placenta abruption [8], preterm delivery $[5,8,10,11]$ and intrauterine fetal death [9]. Moreover, for undiagnosed patients, the outcome was worse in comparison in future pregnancies when ET was treated [9]. Special attention was given in the beneficial role of ASA when was given in patients with known ET, which was continued throughout pregnancy. ASA appeared to increase the percentage of live births with less pregnancy complications $[5,8,9]$.

\section{Platelet apheresis}

There are only few cases reported in which platelet apheresis was performed in order to decrease the platelet count. The courses of platelet apheresis were scheduled mostly at the beginning of the pregnancy [12]. Most of the patients have a history of abortions in the past $[13,14]$; nevertheless, pregnancy complications including intrauterine growth retardation and preeclampsia have been reported [15]. Platelet apheresis was also performed complementary with ASA and low-molecular weight heparin (LMWH) $[16,17]$.

\section{Low dose aspirin and other antiplatelet agents}

Low dose ASA has been frequently used during pregnancy and it is considered safe for the fetus without a significant risk of bleeding for the mother [18]. Due to the increased percentage of abortions and pregnancy complications in untreated patients as results of thrombosis and abnormal placenta blood circulation, the addition of low-dose ASA showed encouraging results. There are reports in patients with a history of abortions that had a successful pregnancy after single treatment with

Correspondence to: Theoni Kanellopoulou, Hematologist, Department of Clinical Hematology-Blood Bank-Hemostasis, Onassis Cardiac Surgery Center, 356, Andrea Sygrou ave. 17674 Kallithea, Greece, E-mail. theokanel@gmail.com

Key words: pregnancy, essential thrombocytosis, treatment, aspirin, interferon

Received: August 10, 2017; Accepted: September 04, 2017; Published: September 07, 2017 
ASA [5,6,8,9,16,19-25]. ASA was also initiated in some cases, if not at the beginning of pregnancy, when a pregnancy complication was present like hypertension disorders, abrutio placenta or IUGR and premature delivery [5,8,25-27].

Even if there is no direct evidence of the efficacy of ASA, it seems possible that ASA increases the rate of successful pregnancies. In one of the largest case series reported, 79 out of $106(74 \%)$ patients treated with ASA during pregnancy had successful pregnancies, while only 80 out of $145(55 \%)$ of the patients not receiving ASA had successful pregnancies [17]. Especially when there is a history of first trimester miscarriages, a study demonstrated that the rate of pregnancy loss was $21 \%$ among patients receiving ASA during the first trimester in comparison to $75 \%$ among patients who did not [2]. However, in other studies, the positive effect of ASA was not provided [28].

JAK2V617F mutation is known to increase thrombosis rate outside pregnancy. Thus, patients caring this mutation possibly are at increased risk for abortions and pregnancy complications during pregnancy and candidates to receive ASA. Passamonti et al. reported better pregnancy outcome within the JAKV617F positive pregnancies when ASA was given. In this study, complications occurred in $36 \%$ of patients who received ASA in contrary to $68 \%$ who did not receive [29].

Except for ASA other antiplatelet agents like clopidogrel [30] and combination ASA with dipyridamole [17] were rarely given during pregnancy. No side effects or fetal complications were reported.

ASA is contraindicated in patients with a bleeding diathesis, particularly, if the platelet count increases above $1000000 / \mu \mathrm{L}$ because the possibility of an acquired von Willebrand syndrome is increased.

\section{Low molecular weight heparin}

As there are no trials evaluating the role of heparin throughout a high-risk ET pregnancy, the precise benefit is unclear. Thus, prophylactic use of anticoagulation with LMWH is not recommended throughout pregnancy especially in the absence of thrombosis and is not reported to be superior to ASA alone.

There are reports where LMWH was given $[8,9]$. LMWH was also given when ASA was contraindicated due to increased risk of bleeding. In the majority of cases LMWH was combined with ASA $[32,33]$ especially when there was a thrombotic history or a history of pregnancy complications $[28,34,35]$.

In the absence of other thrombophilic factors or presence of placenta-mediated complications, patients are at increased risk of thromboembolic events during the last few weeks of pregnancy and in the postpartum period. At this time, prophylactic dose of LMWH has an important role in the prevention of thrombosis. Griesshammer et al. presented a large case series and patients with ET were under treatment with ASA which stopped about two weeks before labour was expected and started with LMWH in prophylactic dosage. LMWH was continued until delivery, with a dose stopped immediately about 12 hours before the expected delivery and was restarted on the first postpartum day and continued for 6 weeks [36].

\section{Anagrelide}

Anagrelide is not recommended during pregnancy or while conceiving [37], because there are inadequate data if the recommended human doses of anagrelide have adverse effects in pregnancy or influence the fetus. The main concern is the possible thrombocytopenia that anagrelide could cause to the fetus while passing the placenta.
However, there are single cases published in literature while anagrelide was given during pregnancy that resulted either in abortion or live birth [37].

\section{Hydroxycarbamide (Hydroxyurea)}

In animal studies, teratogenicity and embryotoxicity of hydroxycarbamide (hydroxyurea-HU) have been described, but there are no adequate safety data for the use of HU in pregnant women [38].

Most of reported cases are from women with sickle cell disease or chronic myelogenous leukemia and were exposed to HU mostly during first trimester [39]. The majority of patients have been exposed to HU before the diagnosis of pregnancy and before 8 weeks of gestation $[17,40,41]$. However, there are single cases that $\mathrm{HU}$ was continued until the second and third trimester [41,42]. Interestingly, many of the patients had a previous history of abortion when ET was not diagnosed or when cytoreductive treatment was not given for ET before the abortion $[42,43]$. No major maternal complications or fetal malformations have been reported.

\section{Interferon-a}

Currently, IFNa is the treatment of choice during pregnancy and is used with an off-label indication (FDA drug - category C). In most of the cases IFNa was combined with ASA and women that were candidates for treatment had a history of abortions or pregnancy complications in the past.

Treatment recommendations of patients with criteria of cytoreductive treatment (like platelet count $>1500000 / \mu$ l or thrombosis) while conceiving, suggest IFNa to be the safest option. Thus, there are case reports under treatment with IFNa in early pregnancy before the identification of pregnancy [43-45]. In pregnancies that were considered "high risk" or there was a history of abortions or pregnancy complications including intrauterine fetal death IFNa was continued in all trimesters or the initiation was done when other complications were present like IUGR. In almost all cases IFNa was combined with ASA $[9,16,25,31,46-51]$.

Severe adverse events were not reported; nevertheless there is a reported case of an infant with neonatal lupus and thrombocytopenia in a patient that was exposed to IFNa during pregnancy [52].

\section{Pegylated interferon-a}

There are currently limited data about the safety and efficacy of pegylated-interferon a (Peg-IFNa) in pregnant ET patients. Anecdotal use of Peg-IFNa in pregnant patients with hepatitis or myeloproliferative disorders (including ET) has been reported with encouraging results concerning safety and disease remission [53-57].

Beauverd et al. reported 10 pregnancies and Peg-IFNa had been well tolerated which allowed control of platelet count during pregnancy, and was associated with a high live birth rate (90\%) and low miscarriage rate $(10 \%)$ even if $75 \%$ of patients were considered high risk. None of the patients reported severe adverse events that resulted in discontinuation of treatment. All cases were also treated with ASA and neither major bleeding nor thrombosis was reported antepartum or postpartum and none stillbirth or infant malformation was described. There were significantly more live births on peg-IFN and fewer miscarriages. When LMWH was added to treatment there was a trend towards a better outcome even not statistically significant [19]. In addition, another successful high-risk pregnancy has been reported under treatment with Peg-IFN combined with ASA and LMWH. This 
was the only successful pregnancy, which produced a healthy baby since she has a history of miscarriages and pregnancy complications (stillbirth, hypertension, neonatal death) in the past [58,59].

\section{Discussion}

Treating women with ET during pregnancy is challenging because patients are at increased risk for first trimester spontaneous abortions, thrombotic and obstetric complications, whereas cytoreductive therapy might have harmful effects on the fetus. It has been recommended cytoreductive agents to be avoided, particularly in the first trimester and none is licensed for use in pregnancy.

Women who have an unplanned pregnancy on $\mathrm{HU}$ should stop treatment and inform their physicians in time in order to take early decision about pregnancy termination. Anagrelide is also contraindicated during pregnancy. Pregnant women who are candidates for platelet-lowering therapy according to general guidelines of ET treatment should receive IFNa which seems to be the safest option for all patients while trying conceiving. Treatment with peg-IFN is more attractive due to the longer half-life and the similar efficacy in controlling platelet count; nevertheless, there is limited data concerning safety profile $[18,29,36]$.

Treatment with ASA might positively influence the outcome of pregnancy due to reduced probability of placental infarctions. Reports of case series of patients that received low dose ASA showed increase in live births and fewer miscarriages or other pregnancy complications $[2,29]$. The addition of LMWH is not recommended even if there are published reports of successful pregnancies after the combination of both drugs in women with history of severe pregnancy complications including fetal death. However, LMWH is reasonable to be considered in women with history of thromboembolic events in the past and high-risk pregnancies for thrombotic potential (for instance immobilization, twin-pregnancies, high body weight of the patient) or presence of antiphosphilipid syndrome [36]. Inherited thrombophilia like presence of heterozygous F-Leiden mutation, in the absence of positive thrombotic family history, is not a definite indication for anticoagulation in all trimesters. However, special attention should be made during third trimester when LMWH should be initiated until six weeks postpartum.

The results of published cases possibly include bias concerning the high rates of miscarriages and pregnancy complications because there is a trend to publish the adverse pregnancy outcome or how to approach a patient with a high-risk pregnancy or with a past history of miscarriages and severe complications including IUGR or fetal death. Thus, prospective studies are needed in order to reconsider the risk of pregnancies, to find the patients who could benefit of more intensive anticoagulation or cytoreductive treatment focusing on the safety of drugs for both the pregnant patient and the fetus.

\section{References}

1. Passamonti F, Randi ML, Rumi E, Pungolino E, Elena C, et al. (2007) Increased risk of pregnancy complications in patients with essential thrombocythemia carrying the JAK2 (617V $>$ F) mutation. Blood 110: 485-489. [Crossref]

2. Gangat N, Wolanskyj AP, Schwager S, Tefferi A (2009) Predictors of pregnancy outcome in essential thrombocythemia: a single institution study of 63 pregnancies. Eur J Haematol 82: 350-353. [Crossref]

3. Hoagland HC, Silverstein MN (1978) Primary thrombocythemia in the young patient. Mayo Clin Proc 53: 578-580. [Crossref]

4. Linares M, Pastor E, Jarque I, Sanz G, Sanz M (1988) Essential thrombocythemia and pregnancy. Am J Hematol 28: 66. [Crossref]
5. Randi ML, Rossi C, Fabris F, Girolami A (1999) Essential thrombocythemia in young adults: treatment and outcome of 16 pregnancies. J Intern Med 246: 517-518. [Crossref]

6. Candoni A, Fanin R, Michelutti T, Russo D, Michelutti A (2002) Pregnancy and abortion in women with essential thrombocythemia. Am J Hematol 69: 233-234. [Crossref]

7. Kaibara M, Kobayashi T, Matsumoto S (1985) Idiopathic thrombocythemia and pregnancy: report of a case. Obstet Gynecol 65: 18S-19S. [Crossref]

8. Radaelli F, Colombi M, Maiolo AT (1994) Essential thrombocythemia in pregnancy: report of four cases. Haematologica 79: 360-363. [Crossref]

9. Puyade M, Cayssials E, Pierre F, Pourrat O. Pregnancy and myeloproliferative neoplasms: A retrospective monocentric cohort. Obstetric Medicine in Press.

10. Bellucci S, Janvier M, Tobelem G, Flandrin G, Charpak Y, et al. (1986) Essentia thrombocythemias. Clinical evolutionary and biological data. Cancer 58: 2440-2447. [Crossref]

11. Frezzato M, Ruggeri M, Castaman G, Rodeghiero F (1993) Polycythemia vera and essential thrombocythemia in young patients. Haematologica 78: 11-17. [Crossref]

12. Relakis C, Kyriakou D, Makrigiannakis AS, Kalokyri I, Datseris G, CoumantakisE, et al. (1996) Successful pregnancy in a young woman with essential thrombocythemia treated with platelet apheresis. Haematologia (Budap) 27: 197-200. [Crossref]

13. Mercer B1, Drouin J, Jolly E, d'Anjou G (1988) Primary thrombocythemia in pregnancy: a report of two cases. Am J Obstet Gynecol 159: 127-128. [Crossref]

14. Yamaguchi K, Hisano M, Sakata M, Minatogawa Y, Suzuki T, Ozawa N et al. (2006) Periodic plateletpheresis during pregnancy in a high-risk patient with essential thrombocythemia. J Clin Apher 21: 256-259. [Crossref]

15. Falconer J, Pineo G, Blahey W, Bowen T, Docksteader B, Jadusingh I (1987) Essential thrombocythemia associated with recurrent abortions and fetal growth retardation. $\mathrm{Am}$ J Hematol 25: 345-347. [Crossref]

16. Beard J1, Hillmen P, Anderson CC, Lewis SM, Pearson TC (1991) Primary thrombocythaemia in pregnancy. Br J Haematol 77: 371-374. [Crossref]

17. Barbui T, Barosi G, Grossi A, Gugliotta L, Liberato LN, Marchetti M, et al. (2004) Practice guidelines for the therapy of essential thrombocythemia. A statement from the Italian Society of Hematology, the Italian Society of Experimental Hematology and the Italian Group for Bone Marrow Transplantation. Haematologica 89: 215-232. [Crossref]

18. Pai SG1,2, Kaplan JB1,2, Giles FJ1, et al. (2016) Long-acting interferon for myeloproliferative neoplasms - an update. Expert Rev Hematol 9: 915-917. [Crossref]

19. Beauverd Y, Radia D, Cargo C, Knapper S, Drummond M, Pillai A, et al. (2016) Pegylated interferon alpha-2a for essential thrombocythemia during pregnancy: outcome and safety. A case series. Haematologica 101: e182-184. [Crossref]

20. Pardini S, Careddu MF, Dore F, Bonfigli S, Gigliotti B, et al. (1995) Essential thrombocythemia and pregnancy. Haematologica 80: 392-393. [Crossref]

21. Okayasu N, Murata M, Ueda A, Su KM, Sada T, Ito T, et al. (1981) Primary thrombocythemia and myocardial infarction in a 26-year-old woman with normal coronary arteriogram. Jpn Heart J 22: 439-445. [Crossref]

22. Dinas K, Hatzipantelis E, Karasmanis K, Zepiridis L, Mavromatidis G, et al. (2008) Improving the outcome of pregnancy in essential thrombocythaemia: The role of aspirin. J Obstet Gynaecol 28: 236-237. [Crossref]

23. Minkhorst AG1, Nováková IR, van Dongen PW (1991) Idiopathic thrombocythemia and pregnancy; a case report. Eur J Obstet Gynecol Reprod Biol 40: 237-238. [Crossref]

24. Eliyahu S, Shalev E (1997) Essential thrombocythemia during pregnancy. Obstet Gynecol Surv 52: 243-247. [Crossref]

25. Palandri F, Polverelli N, Ottaviani E, Castagnetti F, Baccarani M, et al. (2010) Longterm follow-up of essential thrombocythemia in young adults: treatment strategies, major thrombotic complications and pregnancy outcomes. A study of 76 patients Haematologica 95: 1038-1040. [Crossref]

26. Ferrari A, Mazzucconi MG, Martinelli E, Giona F, Paesano R, et al. (1989) Pregnancy in a young woman affected by essential thrombocythemia: a case report. Haematologica 74: 115-116. [Crossref]

27. Pineo GF, Blahey WB (1991) Essential thrombocythemia and complications of pregnancy. Am J Hematol 36: 221. [Crossref]

28. Wright CA, Tefferi A (2001) A single institutional experience with 43 pregnancies in essential thrombocythemia. Eur J Haematol 66: 152-159. [Crossref] 
29. Passamonti F, Rumi E, Randi ML, Morra E, Cazzola M (2010) Aspirin in pregnant patients with essential thrombocythemia: a retrospective analysis of 129 pregnancies. $J$ Thromb Haemost 8: 411-413. [Crossref]

30. De Santis M, De Luca C, Mappa I, Cesari E, Mazza A, et al. (2011) Clopidogrel treatment during pregnancy: a case report and a review of literature. Intern Med 50: 1769-1773. [Crossref]

31. Buyukbayrak EE, Ergen B, Karageyim Karsidag AY, Kars B, Turan C, et al. (2010) Successful pregnancy in a patient with portal hypertension secondary to portal vein thrombosis due to essential thrombocythaemia: a rare case. J Matern Fetal Neonatal Med 23: 187-189. [Crossref]

32. Politou M, Valsami S, Gkorezi-Ntavela I, Telonis V, Merkouri E, ChristopoulosP. A Successful Mother and Neonate Outcome for a Woman with Essential Thrombocytosis and FV Leiden Heterozygosity. Case Rep Obstet Gynecol 2016: 7041686. [Crossref]

33. Klinzing P, Markert UR, Liesaus K, Peiker G (2001) Case report: successful pregnancy and delivery after myocardial infarction and essential thrombocythemia treated with clopidrogel. Clin Exp Obstet Gynecol 28: 215-216. [Crossref]

34. Doubek M, Brychtova Y, Doubek R, Janku P, Mayer J (2004) Anagrelide therapy in pregnancy: report of a case of essential thrombocythemia. Ann Hematol 83: 726-727. [Crossref]

35. Pagliaro P1, Arrigoni L, Muggiasca ML, Poggio M, Russo U, et al. (1996) Primary thrombocythemia and pregnancy: treatment and outcome in fifteen cases. $\mathrm{Am} \mathrm{J}$ Hematol 53: 6-10. [Crossref]

36. Griesshammer M, Struve S, Harrison CM (2006) Essential thrombocythemia/ polycythemiavera and pregnancy: the need for an observational study in Europe. Semin Thromb Hemost 32: 422-429. [Crossref]

37. Sobas MA, Pérez Encinas MM, Rabuñal Martinez MJ, Quinteiro García C, Bello López JL (2009) Anagrelide treatment in early pregnancy in a patient with JAK2V617Fpositive essential thrombocythemia: case report and literature review. Acta Haematol 122: 221-222. [Crossref]

38. Liebelt EL, Balk SJ, Faber W, Fisher JW, Hughes CL, Lanzkron SM, et al. (2007) NTP-CERHR expert panel report on the reproductive and developmental toxicity of hydroxyurea. Birth Defects Res B Dev Reprod Toxicol 80: 259-366. [Crossref]

39. Thauvin-Robinet C, Maingueneau C, Robert E, Elefant E, Guy H, et al. (2001) Exposure to hydroxyurea during pregnancy: a case series. Leukemia 15: 1309-1311. [Crossref]

40. Cinkotai KI, Wood P, Donnai P, Kendra J (1994) Pregnancy after treatment with hydroxyurea in a patient with primary thrombocythaemia and a history of recurrent abortion. J Clin Pathol 47: 769-770. [Crossref]

41. Randi ML, Rossi C, Fabris F, Girolami A (1999) Essential thrombocythemia in young adults: treatment and outcome of 16 pregnancies. J Intern Med 246: 517-518. [Crossref]

42. Oskuie AE, Valizadeh N (2011) Successful outcome of pregnancy in a case of essential thrombocytosis treated with hydroxyurea. Indian J Cancer 48: 268-269. [Crossref]

43. Petit JJ, Callis M, Fernandez de Sevilla A (1992) Normal pregnancy in a patient with essential thrombocythemia treated with interferon-alpha 2b. Am J Hematol 40: 80. [Crossref]

44. Pardini S, Dore F, Murineddu M, Bontigli S, Longinotti M, et al. (1993) Alpha $2 \mathrm{~b}$-interferon therapy and pregnancy--report of a case of essential thrombocythemia. Am J Hematol 43: 78-79. [Crossref]
45. Díez-Martín JL, Banãs MH, Fernández MN (1996) Childbearing age patients with essential thrombocythemia: should they be placed on interferon? Am J Hematol 52: 331-332. [Crossref]

46. Iwashita T, Fujitani M, Yamamoto Y, Katsurada T, Yoshida Y (2006) Interferon-alfa treatment of essential thrombocythemia during pregnancy. Intern Med 45: 1161-1164. [Crossref]

47. Lekovic D, Gotic M, Ljubic A (2011) First successful pregnancy outcome after intrauterine insemination in a woman with primary infertility and essential thrombocythemia treated with interferon-alpha and aspirin. Srp Arh Celok Lek 143: 210-213. [Crossref]

48. Singh N, Kumar S, Roy KK, Sharma V, Jalak A (2012) Successful maternal and fetal outcome in a rare case of essential Thrombocythemia with pregnancy using Interferon alpha. Platelets 23: 319-321. [Crossref]

49. Vianelli N, Gugliotta L, Tura S, Bovicelli L, Rizzo N, et al. (1994) Interferon-alpha 2a treatment in a pregnant woman with essential thrombocythemia. Blood 83: 874-875. [Crossref]

50. Thornley S, Manoharan A (1994) Successful treatment of essential thrombocythemia with alpha interferon during pregnancy. Eur J Haematol 52: 63-64. [Crossref]

51. Delage R, Demers C, Cantin G, Roy J (1996) Treatment of essential thrombocythemia during pregnancy with interferon-alpha. Obstet Gynecol 87: 814-817. [Crossref]

52. Fritz M, Vats K, Goyal RK (2005) Neonatal lupus and IUGR following alpha-interferon therapy during pregnancy. J Perinatol 25: 552-554. [Crossref]

53. Ellis M, Mills AK (2015) Successful maintenance of molecular remission in chronic myelogenous leukaemia during pregnancy with transition from imatinib to pegylated interferon. Intern Med J 45: 358-359. [Crossref]

54. Atasoy HI1, Sirmatel P2, Sirmatel F3 (2017) Pegylated interferon therapy during early pregnancy for hepatitis B infection: does it prevent vertical transmission? J Matern Fetal Neonatal Med 30: 745-747. [Crossref]

55. Labarga P, Pinilla J, Cachorro I, Ruiz Y (2007) Infant of 22 months of age with no anomalies born from a HCV-and HIV-infected mother under treatment with pegylated interferon, ribavirin and antiretroviral therapy during the first 16 weeks of pregnancy. Reprod Toxicol 24: 414-416. [Crossref]

56. Melillo L, Tieghi A, Candoni A, Radaelli F, Ciancia R, et al. (2009) Outcome of 122 pregnancies in essential thrombocythemia patients: A report from the Italian registry Am J Hematol 84: 636-640. [Crossref]

57. Harrison CN, Bareford D, Butt N, Campbell P, Conneally E, et al. (2010) Guideline fo investigation and management of adults and children presenting with a thrombocytosis. Br J Haematol 149: 352-375. [Crossref]

58. Jayasekara WM, Abeyratne SA, Kulathilake C, Gunawardena D, Wijesiriwarden IS (2015) Successful management of a pregnancy complicated by essential thrombocythaemia with pegylated interferon. Ceylon Med J 60: 72-73. [Crossref]

59. Masarova L, Patel KP, Newberry KJ, Cortes J, Borthakur G, Konopleva M, et al. (2017) Pegylated interferon alfa-2a in patients with essential thrombocythaemia or polycythaemia vera: a post-hoc, median 83-month follow-up of an open-label, phase 2 trial. Lancet Haematol 4: e165-e175. [Crossref]

Copyright: (C)2017 Kanellopoulou T. This is an open-access article distributed under the terms of the Creative Commons Attribution License, which permits unrestricted use, distribution, and reproduction in any medium, provided the original author and source are credited. 